\section{Master your practice management}

An ever-evolving dental industry and constantly shifting patient demands mean that practices must adapt quickly to always be ahead of the curve.

With Sensei Cloud, this is easier than ever before.

An innovative practice management platform, Sensei Cloud combines Carestream Dental's rich history of practice management systems with the voice of the dental industry, creating a software that not only helps your practice to excel, but that also learns as the industry changes to keep you at the forefront of innovation.

Easy-to-use and perfect for business models of any size, Sensei Cloud is your key to the future of your business.

For more information, contact Carestream Dental on 0800169 9692 or visit www.carestreamdental.co.uk.

\section{Fall in love at first try}

The latest in a long line of tried and tested solutions from 3M Oral Care is RelyX Universal Resin Cement.

Providing a cost-efficient option, the newly designed micro mixing tip leads to $80 \%$ less cement wastage per application compared to standard automix systems. Boosting its green credentials, the new syringe of RelyX Universal Resin Cement from $3 \mathrm{M}$ also uses $50 \%$ less plastic.



Available in four fluorescent shades - TR, A1, A3O and WO - it is adhesive cured and provides superior self-adhesive bond strength to dentine. Combined with the new Scotchbond Universal Plus Adhesive from $3 \mathrm{M}$, it eliminates the hassle and confusion of multiple dental cements for a simple workflow.

Fall in love with the latest solutions from 3M Oral Care - contact the team today.

To find out more and to request a demo of RelyX Universal resin cement, visit www.3M.co.uk/relyx-universal today.

For more information, call 08705360036 or visit www.3M.co.uk/ Dental.

$3 \mathrm{M}$ representatives continue to be available via video calling technologies for your convenience.

$3 \mathrm{M}$, RelyX and Scotchbond are trademarks of the $3 \mathrm{M}$ Company.

\section{Make endodontic treatments clearer and safer}

DENTAMERICA was founded in 1986, dedicated to developing advanced dental technology and innovative products.

Root canal treatment used to be performed with hand files that were easily broken during this complicated process. DENTAMERICA's ENDOMAX BRITE is designed to solve the problems of broken files and insufficient light. It features five unique torques, nine rotation speed settings and LED modules to improve visibility and safety for root canal treatment. It has three modes to solve the issue of broken files:

- Auto-reverse forward mode: When the preset TQ is reached, it will run anti-clockwise until the file is load free, then continue to rotate clockwise

- Auto-reverse stop mode: When the preset TQ is reached, it will run anti-clockwise until the file is load free, then it stops

- Reciprocating mode: It can reach $150^{\circ}$ of positive and negative rotation. The angle can be increased or decreased to $30^{\circ}$ when the function button is pressed.

These functions can help dentists to solve the broken file problem and make treatments safer. In order to solve the light problem, the autoclavable LED module can help to make the root canal treatment process clearer.

Although the COVID-19 pandemic is not over yet, it could be the right moment to digitise your clinical environment. Using the Apixia PSP scanner will help you to speed up the process of taking an $\mathrm{x}$-ray for each patient and Apixia software will provide a clear diagnostic image.

You can find out more at www.dentamerica.com and if you would like to order, contact regional manager Mr Eric Huang, emailinfo@dentamerica.com.

\section{Get planning for 2021!}

It's never too early to draft a business plan for the following year. Given the turbulent landscape of 2020, carefully planning ahead and preparing your dental practice for 2021 will be even more important.

What should this entail? Financial planning will likely be top of the list. You'll need to know exactly what condition your business is in right now, while also predicting potential income and expenses for 2021 - including any deferred repayments from financial holidays utilised while the practice was closed. From here, you'll need to introduce a realistic payment schedule and decide where you could boost revenue to help rebuild cash reserves.

For expert support and bespoke advice on how you could optimise your finances for 2021, the IFAs at money4dentists are available to help.

For more information call 0845345 5060, email info@ money4dentists.com or visit www.money4dentists.com. 